\title{
A farinha de mandioca e as relações Ciência-Tecnologia- Sociedade-Ambiente (CTSA) como valorização do conhecimento tradicional no ensino de ciências.
}

\author{
Mandioca flour and Science-Technology-Society-Environment (STSE) \\ relations as valorization of traditional knowledge in Science educations.
}

Eldrinei Gomes Peres (eldrinei_peres@hotmail.com)

(Universidade Federal do Amazonas, Departamento de Química)

\author{
Klenicy Kazumy de Lima Yamaguchi (klenicy@ gmail.com) \\ (Universidade Federal do Amazonas, Instituto de Saúde e Biotencologia)
}

\begin{abstract}
Resumo: Nos últimos anos, os estudos no ensino de Ciências têm expressado uma preocupação em possibilitar a construção de conhecimentos científicos com intuito de permitir ao indivíduo agir crítica e conscientemente na sociedade, exercendo plenamente sua cidadania. Este trabalho teve como objetivo utilizar a farinha de mandioca e as relações Ciência-Tecnologia-Sociedade-Ambiente (CTSA) aplicada ao ensino de Ciências, agregando conhecimento científico ao conhecimento tradicional dos alunos. A metodologia empregada apresentou caráter qualitativo e quantitativo, com aplicação de questionário inicial e final contendo questões abertas e fechadas. O trabalho foi desenvolvido em uma escola Municipal no interior do Amazonas (Alvarães), no $9^{\circ}$ ano do Ensino Fundamental, com aulas expositivas, atividade lúdica e aula de campo. Por meio deste trabalho pôde-se proporcionar um ensino dialogado e dinâmico com os alunos, relacionando conhecimento científico e conhecimento empírico como forma de valorização das experiências cotidianas e conservação da cultura local. Pôde-se conciliar e relacionar ciência-tecnologia-sociedade e ambiente através da produção de farinha de mandioca, buscando promover um aprendizado significativo.
\end{abstract}

Palavras-chave: CTSA; Conhecimento popular; Amazonas.

Abstract: In recente years, Science education researchs had been show a concern to enable the construction of scientific knowledge in order to allow the individual to act critically and consciously in society, fully exercising their citizenship. This work aimed using Mandioca flour and Science-Technology-Society-Environment (STSE) in traditional representations of scientific knowledge. The methodology employed was qualitative and quantitative, with application of initial and final questionnaire containing open and closed questions. The work was developed in a municipal school in the interior of Amazonas (Alvarães), in the 9th grade of elementary school, with lectures, ludic activity and field class. Through this work can provide a dialogic and dynamic teaching with students, relating scientific knowledge and empirical knowledge of students, as a way of valuing students' daily experiences and conservation of local culture. It can reconcile and relate science-technology-society and environment (STSE) through the production of mandioca flour to promote meaningful learning.

Key words: STSE; Knowledge popular; Amazonas.

Recebido em: 06/05/2020

Aceito em: 26/08/2020 


\section{INTRODUÇÃO}

Nos últimos anos, os estudos no ensino de Ciências têm expressado uma preocupação em possibilitar a construção de conhecimentos científicos com intuito de permitir ao indivíduo agir de forma crítica e consciente na sociedade (OTTZ, PINTO, AMADO, 2014). Segundo a Base Nacional Curricular Comum (BRASIL, 2018), faz-se necessário que o ensino de Ciências possibilite habilidades e competências que permitam que o indivíduo tenha uso consciente dos recursos naturais frente aos desafios enfrentados pelo ser humano. Neste sentido, o ensino não deve estar focado apenas no conhecimento centralizado, mas deve contribuir diretamente para a formação do cidadão.

Paralelamente, a falta de contextualização dos conteúdos escolares fragmenta a aprendizagem que, sem conexão com o cotidiano, reproduz um aprendizado mecânico e que pouco contribui para a formação de cidadãos participativos e críticos. Uma das formas de minimizar esse quadro é o uso de estratégias de ensino que envolvam a construção do conhecimento, como o uso de sala de aula invertida, uso de contextualização, atividades lúdicas entre outras (PINHEIRO; CARDOSO, 2020; OTTZ, PINTO, AMADO, 2014). Além disso, a produção do conhecimento deve, também, estar relacionada ao desenvolvimento social, buscando a concretização e aplicação dos conhecimentos em prol de uma sociedade melhor, mais justa e igualitária (REIGOTA, 2007). Para Quadros et al. (2019), “o ensino a partir de temas de interesse dos estudantes, que propiciem a inserção de conceitos científicos, é um pressuposto importante para promover a participação ativa dos estudantes e o envolvimento deles com a Ciência. Essa ideia vem sendo debatida amplamente no âmbito do ensino, em especial a partir do movimento Ciência, Tecnologia e Sociedade e Ambiente (CTSA) e sua relação com a educação científica.

A abordagem CTSA visa auxiliar os discentes a revelarem por si a realidade vivenciada e a aplicação social que o conhecimento representa (SANTOS, 2007; SANTOS, 2008). A princípio, denominado Ciência, Tecnologia e Sociedade (CTS), passou a incorporar as questões ambientais, a fim de integrá-las no meio educacional, passando a CTSA (Ciência-Tecnologia-Sociedade-Ambiente) (VILCHES, GIL-PEREZ, PRAIA, 2011). 
Para Santos e Mortimer (2002) o ensino CTSA é caracterizado como o ensino do conteúdo de Ciências no contexto autêntico do seu meio tecnológico e social. Neste sentido, busca-se integrar a educação científica, tecnológica e social, de tal forma que os conteúdos estudados possam ter uma dimensão que contribua com a discussão de seus aspectos históricos, éticos, políticos e socioeconômicos (LÓPEZ e CEREZO, 1996; SANTOS, 2008).

O movimento CTSA apresenta relevância nas estratégias educacionais, permitindo promover discussões e debates relacionados à produção da ciência e tecnologia e suas consequências para a sociedade contemporânea e o ambiente, conferindo uma voz mais ativa e consciente do povo (AULER, 2002; AULER e BAZZO, 2001; RICARDO, 2007). Desse modo, o professor pode criar situações de aprendizagem diferenciadas, permitindo ao aluno estabelecer conexões entre o conhecimento científico e as situações de seu cotidiano. Essa abordagem envolve uma complexidade de eventos, de concepções filosóficas e crenças em relação à característica do conhecimento científico e à forma como os alunos assimilam determinado conteúdo (SENICIATO e CAVASSAN, 2008) por isto, na maioria das vezes, é um grande desafio para o docente planejar e desenvolver atividades que cumpram com os objetivos do enfoque CTSA e os abordem com eficiência.

Pesquisas vem sendo desenvolvidas associando a abordagem CTSA ao ensino de Ciências, destacando-se: A perspectiva no ensino de Ciências e as questões sociocientíficas (QSC), as concepções e práticas de Professores de Ciências da Natureza do 2. ${ }^{\circ}$ Ciclo do Ensino Básico, além da aplicação utilizando temas ambientais (MARTÍNEZ, 2012; SILVA, SANTOS, KATO, 2016; PARREIRA, 2012).

A busca por abordagens melhores e mais significativas, envolvendo os alunos, vem como uma possiblidade de contribuir na construção do conhecimento. Entre os assuntos que podem ser utilizados no contexto Amazônico, tem-se a produção de farinha de mandioca (Manihot esculenta) como um tema facilitador para ser utilizado na aplicação dos conteúdos de Química, agregando conhecimento científico ao cotidiano dos alunos. Mandioca é o nome pelo qual é conhecida a espécie comestível e mais largamente difundida do gênero Manihot. Este tubérculo comestível é rico em carboidratos, sendo usado tanto na alimentação humana quanto na alimentação animal. Existem evidências diretas e indiretas do cultivo da mandioca que datam de 2500 a.C., e 
possivelmente sua domesticação ocorreu no Noroeste da América do Sul (SAUER, 1993).

Entre os subprodutos da mandioca, tem-se a produção de farinha amarela, onde extrai-se a manipueira, que é considerado um resíduo do processo que, por meio de fermentação e cocção, obtém-se os demais subprodutos, o tucupi e a goma (CAMPOS, et al., 2018). A farinha caracteriza-se num alimento de alto valor energético, possui teor elevado de amido, contém fibras e alguns minerais como potássio, cálcio, fósforo, sódio, ferro, e com grande variação quanto à cor, textura granulométrica, acidez, apresentando problemas, com grande diversidade de tipos, pela falta de padronização (SCHWENGBER, 2005). Este subproduto constitui uma das principais fontes alimentícias difundidas em todo o País, fazendo parte da refeição diária da maioria dos brasileiros, especialmente das regiões Norte e Nordeste.

Sgarbieri (1987) relata que na região Norte, a farinha é extremamente importante para o aporte de energia (20 a 50\% do total) e de ferro (30 a 40\% do total, porém de reduzida biodisponibilidade) ingerida pelas populações rurais e urbanas de baixa renda, sendo mais consumida sob a forma de beijus, mingaus e farofas. De acordo com Ferreira Neto et al. (2003), devido a raiz de mandioca recém-colhida ser um produto altamente perecível (teor de umidade em torno de 60\%), sua utilização por tempo prolongado se dá através de produtos desidratados. A redução do teor de umidade dessas raízes dificulta o desenvolvimento microbiano, evitando a consequente deterioração do produto. Estes produtos desidratados são, principalmente, os diversos tipos de farinhas de mandioca, o amido utilizado tanto no preparo caseiro como industrial e a raspa utilizada para ração animal (VILELA, 1987, citado por FERREIRA NETO et al., 2003).

Assim, o uso de temas do cotidiano relacionado à exemplificação e explicação de conhecimentos populares poderá auxiliar na dinâmica e andamento da aula. Neste sentido, o objetivo deste trabalho é utilizar o método CTSA ao ensino de Ciências, aplicando o conhecimento científico à produção e composição físico-química da farinha, como forma de utilizar a contextualização do ensino, tornando-o mais atrativo e dinâmico e correlacionando o conhecimento empírico e científico, de maneira a valorizar o saber discente, na busca de uma aprendizagem significativa.

\section{METODOLOGIA}

Recebido em: 06/05/2020

Aceito em: 26/08/2020 
A pesquisa realizada apresenta análise qualitativa e quantitativa, a partir da observação, integrando uma pesquisa bibliográfica e pesquisa de campo. Fonseca (2002) aborda que a pesquisa de campo é caraterizada pela investigação, através da coleta de dados com a presença da pessoa, além das pesquisas bibliográfica e/ou documental.

A pesquisa qualitativa é uma abordagem que se preocupa com aspectos da realidade que não podem ser quantificados. Minayo e Sanches (2001) apontam que a pesquisa qualitativa trabalha com o universo de significados, motivos, aspirações, crenças, valores e atitudes. A pesquisa qualitativa busca explicar o porquê das coisas. Diferentemente da pesquisa qualitativa, os resultados da pesquisa quantitativa podem ser quantificados. Segundo Fonseca (2002), a pesquisa quantitativa se centra na objetividade. A utilização conjunta da pesquisa qualitativa e quantitativa permite recolher mais informações do que se poderia conseguir isoladamente.

As atividades foram desenvolvidas seguindo 6 (seis) etapas: Caracterização da escola; Aplicação do questionário inicial; Aulas expositivas; Atividade interdisciplinar; Aula de campo e Aplicação do questionário final. Participaram do projeto nove alunos do $9^{\circ}$ ano do Ensino Fundamental, com idade entre 13 e 16 anos. A quantidade de alunos envolvidos nesse trabalho é o total de alunos que constituem a única turma de $9^{\circ}$ ano. O trabalho foi realizado no mês de junho de 2019 em uma escola no interior do Amazonas, localizada na Estrada Alvarães-Nogueira, na Comunidade rural de Nogueira, município de Alvarães (figura 1). O município de Alvarães tem aproximadamente 40 mil habitantes e fica cerca de $430 \mathrm{Km}$ de Manaus. Grande parte da população executa atividade de agricultura na produção de farinha de mandioca como fonte de renda e para alimentação. A comunidade de Nogueira fica a 14 Km do município. É de difícil acesso, sendo necessária a locomoção por via fluvial ou terrestre, tem aproximadamente 5 mil habitantes, que sobrevivem da agricultura e da pesca. 


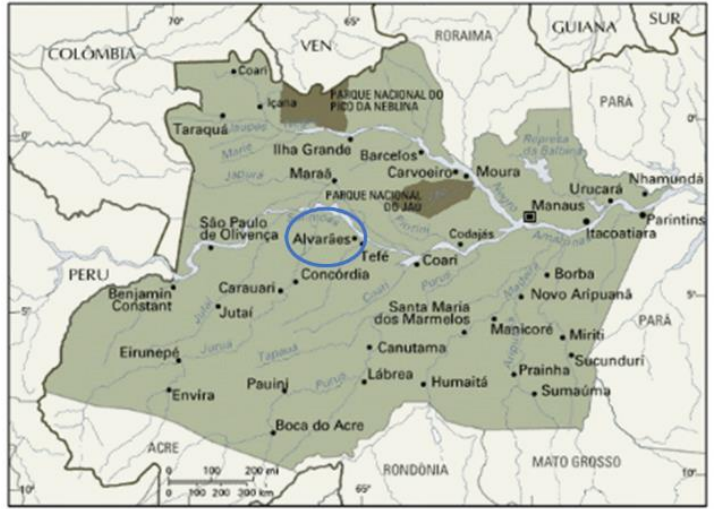

Figura 1: Mapa do Amazonas com localização do município de Alvarães.

As atividades realizadas podem ser visualizadas por meio do quadro 1:

\begin{tabular}{|c|c|}
\hline Atividade / duração & Descrição \\
\hline $\begin{array}{l}\text { Caracterização da } \\
\text { escola } \\
\text { (180 minutos) }\end{array}$ & $\begin{array}{l}\text { A escola oferece Educação Infantil e Ensino Fundamental, atendendo } \\
\text { aproximadamente } 227 \text { alunos e caracteriza-se como uma escola da zona rural. }\end{array}$ \\
\hline $\begin{array}{l}\text { Autorização } \\
\text { (90 minutos) }\end{array}$ & $\begin{array}{l}\text { Entrega dos documentos para autorização dos pais na participação dos filhos no } \\
\text { projeto, autorização de imagens e a explicação geral sobre o projeto a ser } \\
\text { desenvolvido. }\end{array}$ \\
\hline $\begin{array}{l}\text { Questionário inicial } \\
\text { (90 minutos) }\end{array}$ & $\begin{array}{l}\text { Questionário semiestruturado contendo } 25 \text { (vinte e cinco) perguntas, visando } \\
\text { um diagnóstico sobre o conhecimento do assunto em questão }\end{array}$ \\
\hline $\begin{array}{l}\text { Aula expositiva } 1 \\
\text { (90 minutos) }\end{array}$ & $\begin{array}{l}\text { Átomo, elemento e substância química. Tipos de misturas e separação de } \\
\text { misturas, apresentação de exemplos do cotidiano. }\end{array}$ \\
\hline $\begin{array}{l}\text { Aula expositiva } 2 \\
\text { (45 minutos) }\end{array}$ & $\begin{array}{l}\text { Construção e organização da Tabela Periódica. Família, período e número } \\
\text { atômico de cada elemento. }\end{array}$ \\
\hline $\begin{array}{l}\text { Aula expositiva } 3 \\
\text { (45 minutos) }\end{array}$ & $\begin{array}{l}\text { Mandioca; Farinha de mandioca; Processo de produção; Constituição físico- } \\
\text { química; Importância dos nutrientes e a preservação do solo para o cultivo da } \\
\text { mandioca. }\end{array}$ \\
\hline $\begin{array}{l}\text { Atividade lúdica } \\
\text { (45 minutos) }\end{array}$ & $\begin{array}{l}\text { Foi entregue a cada aluno uma tabela periódica impressa para colorir, com isso, } \\
\text { foi solicitado aos alunos pintarem, utilizando lápis de cor, a família dos } \\
\text { elementos químicos de acordo com a cor solicitada pelo professor. Em seguida, } \\
\text { foi localizado na tabela periódica cada elemento constituinte da farinha de } \\
\text { mandioca como por exemplo hidrogênio }(\mathrm{H}) \text {, nitrogênio }(\mathrm{N}) \text {, potássio }(\mathrm{K}) \text {, } \\
\text { dentre outros; e cada nutriente presente no solo como ferro (Fe), cálcio (Ca), } \\
\text { magnésio (Mg), necessários para que haja o crescimento saudável da planta e, } \\
\text { cada aluno indicava no quadro branco a família e o período dos elementos } \\
\text { estudados. }\end{array}$ \\
\hline $\begin{array}{l}\text { Aula de campo } \\
\text { (120 minutos) }\end{array}$ & $\begin{array}{l}\text { Houve o deslocamento com os alunos para uma "casa de farinha". Em seguida, } \\
\text { houve a explicação de todo assunto abordado em sala de aula (Tipos de misturas } \\
\text { e separação de misturas; Elemento e substância química; Constituição físico- } \\
\text { química da farinha de mandioca), mostrando os utensílios utilizados e a função } \\
\text { de cada um, bem como a explicação de cada etapa do processo de produção da } \\
\text { farinha de mandioca. Neste momento, foi abordado e explicado aos alunos o } \\
\text { processo de catação, a filtração no momento da retirada da goma (polvilho), a } \\
\text { decantação na obtenção do polvilho e secagem da massa no tipiti (filtração). } \\
\text { Também foi explicado o processo de peneiração da farinha, secagem e sua } \\
\text { importância. Após essas abordagens, foram sanadas todas as dúvidas dos alunos } \\
\text { em relação ao que foi estudado na aula. }\end{array}$ \\
\hline Questionário final & Ao final do projeto, foi aplicado um questionário contendo 17 (dezessete) \\
\hline
\end{tabular}

Recebido em: 06/05/2020

Aceito em: 26/08/2020 
questões abertas e fechadas, visando avaliar a atividade realizada e a contribuição das metodologias para a aprendizagem.

\section{RESULTADOS E DISCUSSÃO}

Na tabulação dos dados iniciais, verificou-se que a maioria dos alunos gostavam $(66,7 \%)$ das aulas de Ciências ministradas pelo professor, porém, avaliavam as aulas como sendo de nível regular $(55,6 \%)$. Isso evidencia as observações feitas durante as aulas do professor, atendo apenas a aulas tradicionais como metodologia de ensino. Schnetzler (2002) e Fourez (2003) abordam que a carência de metodologias inovadoras, atividades criativas e diversificadas é resultado do desconhecimento dos professores de Ciências em relação às pesquisas voltadas para as inovações didáticas que evidenciam o desempenho adequado na disciplina. Segundo Carvalho e Gil-Pérez (2006), essas inovações didáticas nem sempre são inseridas na sala de aula, afetando consideravelmente o processo de ensino-aprendizagem.

Verificou-se que os assuntos importantes como átomo, elemento químico, matéria, substância química, tipos de mistura e separação de misturas, já haviam sido ministradas para os discentes. A maioria conhecia os tipos de misturas $(88,9 \%)$ e os métodos de separação. Na classificação das espécies químicas em substâncias puras ou misturas, perceberam-se inúmeros equívocos, mostrando a dificuldade dos alunos em diferenciar uma substância pura de uma mistura, refletindo as deficiências conceituais em exemplos simples e de fácil entendimento.

Para Marques (2002) e Freire (2005), a sala de aula, muitas vezes, tem se transformado em um ambiente unilateral, onde os alunos são meros ouvintes e o professor é visto como algo neutro, centro do conhecimento e detentor da razão. Como consequência, observa-se pouca interação, justificando a falta de interesse pela disciplina ou mesmo pelo processo de aprendizado.

Os alunos ainda não tinham visto assunto relacionado à tabela periódica, e como consequência, não sabiam o processo de construção e organização dos elementos químicos. A maioria respondeu que não conseguia relacionar os assuntos estudados em sala de aula com seu cotidiano, mostrando um grande distanciamento conceitual e de significado entre teoria e prática. Neste sentido, de acordo com Serafim (2001), um dos 
grandes problemas no ensino de Ciências é a dificuldade dos alunos em relacionar os assuntos vistos em sala de aula com a realidade a sua volta.

Em relação ao tema norteador, a produção de farinha de mandioca é uma atividade muito presente no dia a dia dos alunos, servindo, principalmente como fonte de alimento, fazendo parte da dieta dos alunos. Todos os alunos responderam conhecer alguém que desenvolve essa atividade, citando, principalmente, sua família (100\%) como exemplo. Sobre os derivados da mandioca, os alunos apontaram a farinha, bolos, biscoitos, tucupi e a farinha de tapioca. 77,8\% disseram já ter feito farinha de mandioca, utilizando como meio de preparo o processo artesanal. A maioria respondeu saber os processos envolvidos, indicando como utensílios utilizados a peneira, paneiro, tipiti, forno, cuia e facão. Na denominação dos utensílios utilizados, os alunos acertaram, na sua totalidade, os utensílios utilizados no processo artesanal, porém, desconheciam as tecnologias desenvolvidas para esse processo como o forno e o triturador mecânicos. Os alunos não conseguiam relacionar os processos de produção de farinha de mandioca com os assuntos de Ciências nem tampouco, conheciam a composição físico-química da mandioca. Para Santos (2005), as atividades empíricas desempenham um papel fundamental no ensino de Ciências, o de aprender por meio do conhecido, tornando o aluno capaz de transformar conceitos abstratos em concretos e significativos.

A maior porcentagem dos alunos $(66,7 \%)$ respondeu nunca ter realizado uma aula prática de Ciências e mostraram-se interessados em participar. As atividades práticas são essenciais no ensino de Ciências, causando no aluno a curiosidade, aquisição de novas ideias e possibilitando a aquisição de novos conhecimentos que, somente na teoria, seriam limitados (ANDRADE; MASSABNI, 2011). A tabela com os resultados de todas as respostas do questionário inicial encontra-se como material complementar do referido artigo (ANEXO 1)

No desenvolvimento da atividade, a partir da aula expositiva, verificou-se uma maior atenção e interesse dos alunos nas aulas ministradas, por meio de perguntas e contribuições acerca dos assuntos abordados. Os resultados da análise referente à aula expositiva encontram-se na tabela 1.

Tabela 1: Dados relacionados às aulas expositivas. Fonte: Os autores (2019).

\section{Dados do questionário final}




\begin{tabular}{|c|c|c|c|}
\hline Perguntas & Respostas & $\mathbf{N}$ & $\begin{array}{c}\text { Percentual } \\
(\%)\end{array}$ \\
\hline \multirow{4}{*}{$\begin{array}{l}\text { 1. Como você avalia as aulas de } \\
\text { Ciências ministradas? }\end{array}$} & Regular & 1 & 12.5 \\
\hline & Boa & 2 & 25.0 \\
\hline & Ótima & 1 & 12.5 \\
\hline & Excelente & 4 & 50.0 \\
\hline \multirow{5}{*}{$\begin{array}{l}\text { 2. Qual(is) do(s) assunto(s) } \\
\text { ministrado(s) você mais gostou ou } \\
\text { teve maior facilidade em } \\
\text { compreender? }\end{array}$} & $\begin{array}{c}\text { Tipos de misturas; } \\
\text { Separação de misturas }\end{array}$ & 8 & 100.0 \\
\hline & Tabela Periódica & 6 & 75.0 \\
\hline & Substância química & 5 & 62.5 \\
\hline & Elemento químico & 4 & 50.0 \\
\hline & Átomo & 1 & 12.5 \\
\hline \multirow{5}{*}{$\begin{array}{l}\text { 3. Qual(is) do(s) assunto(s) } \\
\text { ministrado(s) você menos gostou } \\
\text { ou teve maior dificuldade em } \\
\text { compreender? }\end{array}$} & Substância química & 2 & 25.0 \\
\hline & Elemento químico & 2 & 25.0 \\
\hline & Átomo & 1 & 12.5 \\
\hline & Tabela Periódica & 1 & 12.5 \\
\hline & Separação de misturas & & 12.5 \\
\hline \multirow{2}{*}{$\begin{array}{l}\text { 4. Indique se são (1) substâncias } \\
\text { puras ou (2) misturas. }\end{array}$} & Acertos & 65 & 90.3 \\
\hline & Erros & 7 & 9.7 \\
\hline
\end{tabular}

A avaliação positiva dos alunos sobre as aulas ministradas reflete o que foi visto em sala de aula, um comportamento diferenciado tanto do professor quanto dos alunos. O professor desempenha um papel importante no processo de ensino, funciona como mediador entre os conhecimentos científicos e empíricos, tornando o aluno protagonista de seu próprio conhecimento, deixando de lado a mera aquisição de conceitos (PRAIA; CACHAPUZ, 1994). Nesse sentido, é necessária uma postura e tomada de decisão que vão de encontro ao comodismo e ao sistema vigente nas escolas. Castoldi e Polinarski (2009) afirmam que há nos professores um certo receio em inovar ou mesmo adotar uma metodologia diferenciada em suas aulas, em detrimento do sistema presente nas escolas, fazendo com que optem pelo método tradicional. Segundo Nicola e Paniz (2016), a utilização de novos recursos didáticos torna as aulas mais dinâmicas e possibilita a compreensão de conteúdos considerados complexos, instigando a criatividade e o desenvolvimento de novas habilidades.

Para Freire (2005) e Delizoicov (2001), no processo de aprendizagem, a interação entre professor e aluno torna-se essencial para que ocorra uma aprendizagem significativa. Nesse contexto, a sala de aula deve ser um local de profunda interação 
entre professor e aluno, possibilitando a formação de cidadãos críticos capazes de agir socialmente de forma consciente, capazes de transformar saberes empíricos em conhecimento científico na melhoria de sua vida e de sua comunidade.

A atividade lúdica também teve resultados positivos tanto na avaliação dos alunos quanto nos resultados obtidos, sendo que a maioria dos alunos nunca tinham feito uma atividade lúdica, tendo uma grande aceitação entre eles. Os resultados da atividade lúdica podem ser visualizados na tabela 2.

Tabela 2: Questionário final referente à atividade interdisciplinar e prática de campo. Fonte: Os autores (2020).

\section{Dados do questionário final}

\section{Perguntas}

Respostas

$\mathbf{N}$

Percentual $(\%)$

5. A atividade desenvolvida em sala de aula auxiliou na compreensão do assunto Tabela Periódica?

\begin{tabular}{|c|c|c|c|}
\hline \multirow{4}{*}{$\begin{array}{l}\text { 6. Como você avalia a atividade } \\
\text { desenvolvida em sala de aula? }\end{array}$} & Regular & 1 & 12.5 \\
\hline & Boa & 1 & 12.5 \\
\hline & Ótima & 3 & 37.5 \\
\hline & Excelente & 3 & 37.5 \\
\hline \multirow{2}{*}{$\begin{array}{l}\text { 7. Você gostou da forma como foram } \\
\text { abordados os assuntos? }\end{array}$} & Sim & 7 & 87.5 \\
\hline & Parcialmente & 1 & 12.5 \\
\hline \multirow{3}{*}{$\begin{array}{l}\text { 8. Como você avalia a aula de campo } \\
\text { desenvolvida? }\end{array}$} & Boa & 1 & 14.3 \\
\hline & Ótima & 5 & 71.4 \\
\hline & Excelente & 1 & 14.3 \\
\hline \multirow{2}{*}{$\begin{array}{l}\text { 9. A aula de campo auxiliou na } \\
\text { compreensão dos assuntos? }\end{array}$} & Sim & 6 & 85.7 \\
\hline & Parcialmente & 1 & 14.3 \\
\hline \multirow{2}{*}{$\begin{array}{l}\text { 10. Com a aula de campo ficou mais } \\
\text { fácil a compreensão dos assuntos? }\end{array}$} & Sim & 5 & 71.4 \\
\hline & Parcialmente & 2 & 28.6 \\
\hline $\begin{array}{l}\text { 11. Você compreendeu os processos } \\
\text { envolvidos na produção de farinha de } \\
\text { mandioca? }\end{array}$ & Sim & 8 & 100.0 \\
\hline \multirow{6}{*}{$\begin{array}{l}\text { 12. Indique quais são os derivados da } \\
\text { mandioca. }\end{array}$} & Tucupi; Farinha & 8 & 100.0 \\
\hline & Biscoitos & 5 & 62.5 \\
\hline & Bolos & 7 & 87.5 \\
\hline & $\begin{array}{l}\text { Farinha de } \\
\text { tapioca }\end{array}$ & 7 & 87.5 \\
\hline & Pão & 3 & 37.5 \\
\hline & Bebidas & 2 & 25.0 \\
\hline
\end{tabular}

13. Indique abaixo os utensílios Peneira; Paneiro; utilizados em todo processo de preparo Tipiti; Forno; 8 100.0 da farinha de mandioca. Remo 


\begin{tabular}{llccc} 
& & & & \\
& & Cuia & 7 & 87.5 \\
\cline { 3 - 5 } & Facão & 3 & 37.5 \\
\hline $\begin{array}{l}\text { 15. Denomine os utensílios ilustrados } \\
\text { abaixo, utilizados na produção de } \\
\text { farinha de mandioca. }\end{array}$ & Acertos & 44 & 91.7 \\
\cline { 3 - 5 } & & Erros & 4 & 8.3 \\
\hline
\end{tabular}

Relatos científicos vêm demonstrando que atividades lúdicas associadas ao ensino são estratégias interessantes para as aulas de Ciências, no entanto, tal qual foi observado neste trabalho, essa metodologia nem sempre é utilizada em sala de aula. No artigo de revisão de Pinheiro e Cardoso (2020), os autores evidenciam que o lúdico é pouco explorado como objeto de estudo em pesquisas na área de educação em Ciências e que essa temática apresenta potencial de crescimento no Brasil.

Nicola e Paniz (2016) ressaltam a importância de novos recursos didáticos como forma de aumentar o interesse dos alunos pelas aulas. Isso tornou-se evidente quando os alunos estavam participando das atividades, principalmente relacionadas à aula prática, onde eles puderam ressignificar os conhecimentos sobre processos de produção da farinha, conhecimentos populares que foram acrescidos de conhecimentos científicos.

Os resultados observados na tabela 2 (questões 9 a 15) mostram a importância e o impacto que uma atividade de campo causa na aprendizagem dos alunos, constituindo um recurso didático valioso para o processo de ensino. Corroborando, Souza (2007) afirma que o professor precisa saber quais métodos são necessários para uma aprendizagem mais eficaz e dinâmica, buscando meios de aprimoramento e diversificação dos métodos, conforme a convivência escolar. Para que isso aconteça, faz-se necessário investir no desenvolvimento profissional dos professores e motivá-los oferecendo subsídios para organização/planejamento das aulas e elaboração de material didático (QUADROS et al., 2019)

Krasilchik (2008) afirma que aula de campo é considerada muito importante pela maioria dos professores, porém, são raras as vezes que são utilizadas como ferramenta de ensino, por demandar muito tempo, organização, responsabilidade, dentre outros fatores. Em acréscimo à essa reflexão, Scotergagna e Negrão (2005) destacam a importância da aula de campo, possibilitando a construção e desenvolvimento dos discentes. 
Foi perceptível a importância da utilização da metodologia com prática de campo por meio da participação dos alunos (Figura 2). Foi possível verificar o quanto eles estavam surpresos ao reconhecerem nos materiais, comumente utilizados no seu cotidiano, a aplicação dos conceitos científicos. Segundo Viveiro e Diniz (2009), as aulas de campo possibilitam ao aluno o contato direto com o objeto de estudo, com o ambiente e melhoram a compreensão dos fenômenos, tornando-se uma importante ferramenta para uma aprendizagem significativa em Ciências.

Com a abordagem de questões ambientais envolvendo a importância da preservação do solo e seus nutrientes para o cultivo da mandioca com maior quantidade e qualidade, abordadas tanto na aula teórica quanto na atividade lúdica, foi possível mostrar aos alunos algo mais profundo: a importância da exploração saudável dos recursos naturais e a conexão que envolve os mesmos. Tratar essas questões através do debate em sala de aula, inseriu os alunos em um universo comum e pouco conhecido. Nesse sentido, a abordagem utilizada possibilitou apresentar a ciência e os assuntos de forma integrada e mais completa, evidenciando os impactos socioambientais causados pela ciência e tecnologia (GIL; VILCHES, 2004; VILCHES; GIL, 2010).

É necessário incentivar e possibilitar aos alunos uma visão crítica, responsávele participativa dos anseios da sociedade como justiça, igualdade e sustentabilidade. A iniciativa e tomada de decisões são os primeiros passos na busca por interesses comuns (COUTINHO et. al., 2014; VÁZQUEZ; MANASSERO, 2012, 2016; VILCHES; GIL, 2010).

Verificou-se que os alunos passaram a ter uma compreensão mais clara e significativa dos conceitos teóricos e práticos apresentados, adquirindo uma visão mais ampla e integrada da ciência, contribuindo para o desenvolvimento pessoal e social dos mesmos. A partir da abordagem, foi possível mostrar aos alunos as quatro vertentes subjetivas à produção de farinha de mandioca: A Ciência na abordagem na constituição físico-química da mandioca, da farinha e do solo; a Tecnologia desenvolvida na otimização do processo de cultivo da mandioca e produção da farinha; os Benefícios e a importância da mandioca e seus derivados para a sociedade, e a importância da preservação do solo e dos nutrientes presente nele para o desenvolvimento adequado da planta. 


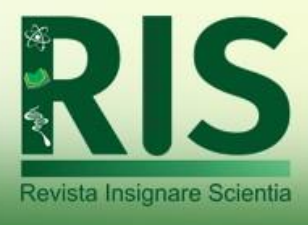

Vol. 3, n. 5. Set./Dez.

ISSN: 2595- 4520

Os resultados descritos nesse trabalho incentivam um ensino contextualizado e aplicado às temáticas sociais, econômicas e ambientais, possibilitando ao aluno a aquisição de novos conhecimentos, novas ideias e contribuindo com a transformação do mundo ao seu redor.

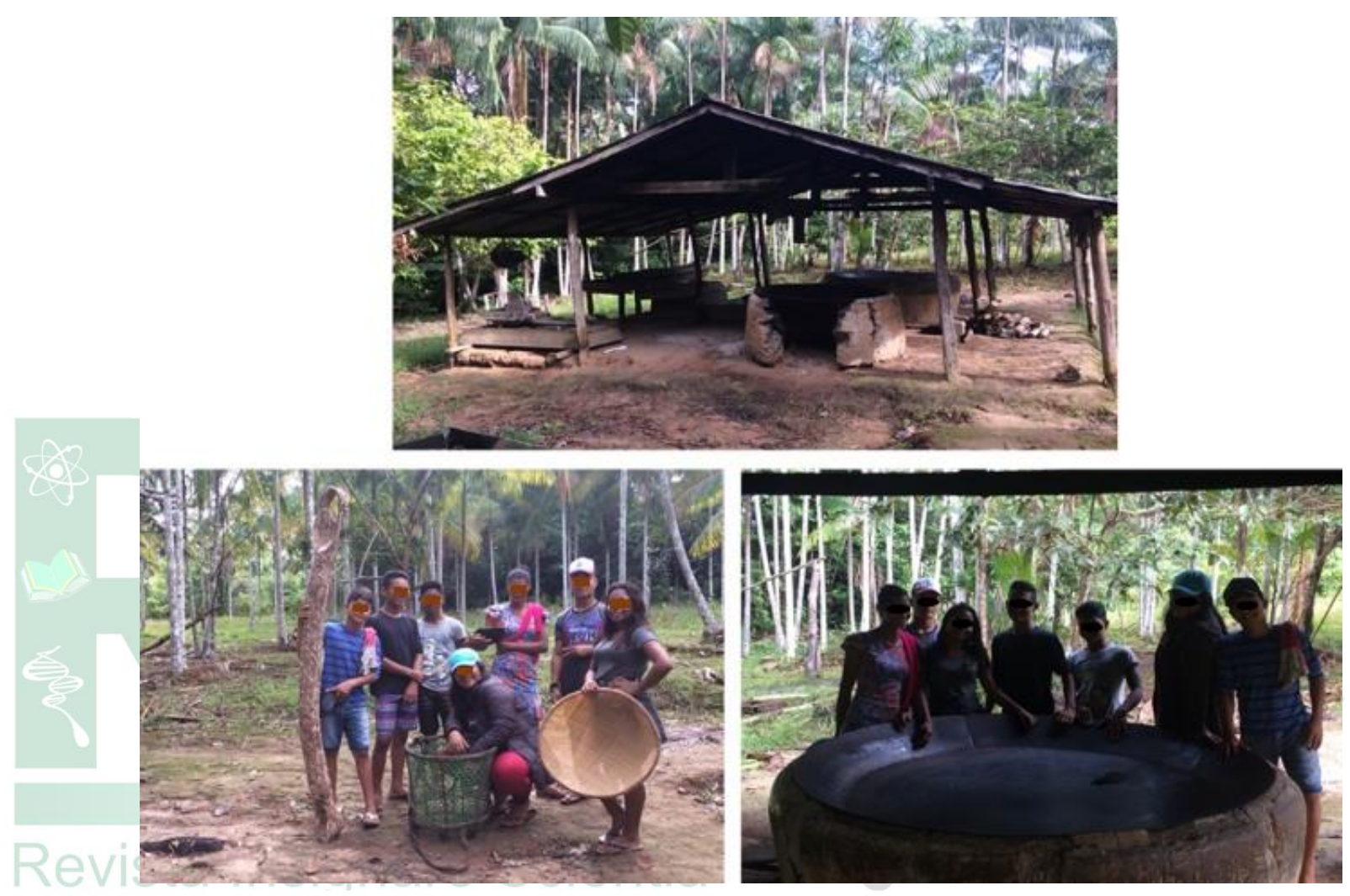

Figura 2: Aula de campo. Fonte: Os autores (2020).

\section{CONSIDERAÇÕES FINAIS}

O trabalho realizado obteve resultados positivos por meio do uso de uma atividade presente no dia a dia dos alunos, realizado pelos alunos e sua família, sendo os mesmos, capazes de entender as questões científicas, tecnológicas, sociais e ambientais envolvidas no cultivo e produção da farinha de mandioca.

Os resultados mostram a eficácia da abordagem CTSA em um contexto educacional de carência de infraestrutura de laboratórios e tecnologias, porém ficando evidente que estratégias metodológicas podem superar as barreiras e complementar as lacunas deixadas pelo tradicionalismo. Essas ferramentas didáticas são de grande 
relevância, pois viabilizam um ensino diferenciado com intuito de uma aprendizagem significativa para os alunos, e melhoramento do desempenho nas aulas de Ciências.

\section{REFERÊNCIAS}

ANDRADE, M. L. F.; MASSABNI, V. G. O desenvolvimento de atividades práticas na escola: Um desafio para professores de Ciências. Ciência \& Educação, v.17, n.4, p. 835-854, 2011.

AULER, D. Interação entre Ciência, Tecnologia e Sociedade no contexto da formação de professore de ciências. 2002. 257 f. Tese (Doutorado em Educação: Ensino de Ciências Naturais), Universidade Federal de Santa Catarina - UFSC, Florianópolis, 2002.

AULER, D.; BAZZO, W. A. Reflexões para implementação do movimento CTS no contexto educacional brasileiro. Ciência \& Educação, v. 7, n.1, p. 1-13, 2001.

BRASIL. Base Nacional Comum Curricular. Brasília: MEC, 2018. Disponível em: http://basenacionalcomum.mec.gov.br/images/historico/BNCC_EnsinoMedio_embaixa site 110518.pdf. Acesso em: 14 de novembro de 2019.

CAMPOS, A. P. R.; MATTIETTO, R.A.; CARVALHO, A. V. Optimization of parameters technological to process tucupi and study of product stability. Food Science and Technology, v. 39, n. 2, p. 365-371, 2019 . Disponível em $<$ http://www.scielo.br/scielo.php?script=sci_arttext\&pid=S0101-

20612019000200365\&lng=pt\&nrm=iso>. acesso em: 19/6/2020. https://doi.org/10.1590/fst.30817.

CARVALHO, A. M. P.; GIL-PÉREZ, D. Formação de professores de Ciências. Tradução de Sandra Valenzuela. São Paulo: Cortez, 2006.

CASTOLDI, R.; POLINARSKI, C. A. A utilização de Recursos didáticopedagógicos na motivação da aprendizagem. In: SIMPÓSIO NACIONAL DE ENSINO DE CIÊNCIA E TECNOLOGIA, 1, Ponta Grossa, 2009. Anais do I SINECT. Disponível em: <http://www.sinect.com.br/anais2009/artigos/8\%20Ensinodecienciasnasseriesin iciais/Ensinodecienciasnasseriesinicias_Artigo2.pdf>. Acesso em: 10 mai. 2019.

COUTINHO, F. A.; MATOS, S. A.; SILVA, F. A. R. Aporias dentro do movimento Ciências, Tecnologia, Sociedade e Ambiente: Apontamentos para uma solução. Revista Sociedade Brasileira do Ensino de Biologia - SBEnBio, v. 7, p. 2176-2185, 2014.

DELIZOICOV, D. Problemas e Problematizações. In: PIETROCOLA, Mauricio (organizador) Ensino de Física: Conteúdo, metodologia e epistemologia numa concepção integradora. Florianópolis: UFSC, 2001. p 125-150.

FEREIRA NETO, C. J.; FIGUEIREDO, R. M. F.; QUEIROZ, A. J. M. Avaliação físico - química de farinhas de mandioca durante o armazenamento. Revista Brasileira de Produto Agroindustrial, v.5, n. 1, p.25-31, 2003.

FREIRE, P. Pedagogia do oprimido. São Paulo: Paz e Terra, 2005.

FONSECA, J. J. S. Metodologia da pesquisa científica. Fortaleza: UEC, 2002. Apostila.

Recebido em: 06/05/2020

Aceito em: 26/08/2020 
FOUREZ, G. Crise no Ensino de Ciências? Investigações em Ensino de Ciências, v. 8, n. 2, p. 109-123, 2003.

GIL, D.; VILCHES, A. Contribución de la ciencia a la cultura ciudadana. Cultura y Educación, Barcelona, v. 16, n. 3, p. 259-272, 2004. Disponível em: <https://doi. org/10.1174/1135640042360924>. Acesso em: 14 abr. 2020.

KRASILCHIK, M. Prática de ensino de biologia. $4^{\text {a }}$ ed., São Paulo: Editora Edusp, 2008 .

LÓPEZ, J. L. L.; CEREZO, J. A. L. Educación CTS en acción: enseñanza secundaria yuniversidad. In: GARCÍA, M. I. G., CEREZO, J. A. L., LÓPEZ, J. L. L. Ciencia, tecnologia y sociedad: una introducción al estudio social de la ciencia y la tecnología. Madrid: Editorial Tecnos S. A, 1996.

NICOLA, J. A.; PANIZ, C. M. A importância da utilização de diferentes recursos didáticos no ensino de biologia. Infor, Inov. Form., Revista NEaD-Unesp, São Paulo, v. 2, n. 1, p.355-381, 2016.

MARQUES, M. O. Educação nas Ciências: interlocução e complementaridade. Ijuí: Unijuí, 2002.

MARTÍNEZ, L. F. P. Ensino de ciências com enfoque ciência, tecnologia, sociedade e ambiente (CTSA) a partir de questões sociocientíficas (QSC). In: Questões sociocientíficas na prática docente: Ideologia, autonomia e formação de professores [online]. São Paulo: Editora UNESP, 2012, pp. 55-61. Available from SciELO Books <http://books.scielo.org>. Acesso em: 12 mai. 2019.

MINAYO, M. C. de S.; SANCHES, O. Quantitativo-qualitativo: oposição ou complementaridade?.Ano Disponível em

http://www.scielosp.org/scielo.php?pid=S0102

311X1993000300002\&script=sci_arttext $>$. Acesso em: 12 mai. 2019.

PARREIRA, S. A. N. Perspectiva CTSA (Ciência, Tecnologia, Sociedade e Ambiente) no Ensino de Ciências: concepções e práticas de Professores de Ciências da Natureza do 2. ${ }^{\circ}$ Ciclo do Ensino Básico. Instituto Politécnico de Bragança. Escola de Ensino Superior. 2012.

OTTZ, P. R. C.; PINTO, A. H.; AMADO, M. V. Aprendizagem Baseada na Resolução de Problemas e a temática "Agricultura e Alimentos": Um enfoque no cultivo da mandioca. Vitória: Instituto Federal de Educação, Ciência e Tecnologia do Espírito Santo. ed. Ifes, 2014.

PINHEIRO, A.; CARDOSO, S. O lúdico no ensino de ciências: uma revisão na Revista Brasileira de Pesquisa em Educação em Ciências. Revista Insignare Scientia - RIS, v. 3, n. 1, p. 57-76, 2020.

PRAIA, J.; CACHAPUZ, F. Un Análisis de Las Concepciones acerca de la Naturaleza del Conocimiento Cientifico de los Profesores Portugijese de la Enseñanza Secundaria. Enseñanza de las Ciencias, p. 350-354, v. 12, n. 3,1994.

QUADROS, A.; FERNANDES, G.; DIAS, M.; DE ALMEIDA, L. O entendimento de professores experientes ao serem desafiados a desenvolver o ensino de Química a partir de temas do contexto social. Revista Insignare Scientia, v. 2, n. 4, p. 62-78, 2019. 
REIGOTA, M. A. S. Ciência e sustentabilidade: a contribuição da educação ambiental. Revista de Avaliação da Educação Superior, v. 12, n. 2, jun. 2007.

RICARDO, E.C. Educação CTSA: obstáculos e possibilidades para implementação no contexto escolar. Ciência \& Ensino, v. 1, n. especial, 2007.

SANTOS, W. L. P. dos. Contextualização no Ensino de Ciências por meio de temas CTS em uma perspectiva crítica. Ciência \& Ensino, v.1, número especial, 2007.

SANTOS, W. L. P. Educação científica humanística em uma perspectiva freireana: resgatando a função do ensino de CTS. Alexandria: Revista de Educação em Ciência e Tecnologia, v. 1, n. 1, p. 109-131, 2008. Disponível em: <https://periodicos.ufsc.br/index.php/alexandria/article/view/37426>. Acesso em: 19/6/2020.

SANTOS, W. L. P.; MORTIMER, E. F. Uma análise de pressupostos teóricos da abordagem CTS (Ciência-Tecnologia-Sociedade) no contexto da educação brasileira. Ensaio: Pesquisa em Educação em Ciências, Belo Horizonte, v.2, n.2, p.133-162, 2002.

SANTOS, C. S. Ensino de ciências: abordagem histórico-crítica. Campinas, SP: Autores Associados, 2005.

SAUER, J. D. Historical Geografy of Crop Plants: a select roster. CRC Press: Boca Raton, Ann Arbot, London, Tokyo. 1993.

SCHNETZLER, R. P. Práticas de ensino nas ciências naturais: desafios atuais e contribuições de pesquisa. In: Didática e Práticas de Ensino; Revista Univap, São José dos Campos-SP, v. 17, n. 30, dez.2011. saberes e lugares formativos. ROSA, Dalva E. Gonçalves et al. (organizadores). Rio de Janeiro: DP\&A, 2002.

SCHWENGBER, D. R. A expansão da cultura da mandioca em Roraima. EMBRAPA/CPAFRR. 2005.

SCORTEGAGNA, A.; NEGRÃO, O. B. M. Trabalhos de campo na disciplina de Geologia Introdutória: a saída autônoma e seu papel didático. Terrae Didática, Campinas, v. 1, n. 1, p. 36-43, 2005. Disponível em: <http://www.ige.unicamp.br/terraedidatica/v1/pdf-v1/p036- 043_scortegagna.pdf >. Acesso em: 10 mai. 2019.

SENICIATO, T.; CAVASSAN, O. Afetividade, motivação e construção de conhecimento científico nas aulas desenvolvidas em ambientes naturais. Ciências \& Cognição, v.13, n.3, p. 120-136, 2008.

SERAFIM, M. C. A Falácia da Dicotomia Teoria-Prática. Revista Espaço Acadêmico, n. 7, 2001. Disponível em: < http://www.espacoacademico.com.br/007/07mauricio.htm >. Acesso em: 10 mai. 2019.

SILVA, F. A. R.; SANTOS, F. C. dos; KATO, D. S. Abordagem CTSA no Ensino de Ciências: Análises dos últimos anais dos encontros de Ensino de Ciências e Biologia no Brasil. Revista da SBEnBIO - $\quad N^{\circ} \quad 9 \quad-\quad 2016$. https://www.researchgate.net/publication/320384160. Acesso em: 12 mai. 2019.

SOUZA, S. E. O uso de recursos didáticos no ensino escolar. In: I ENCONTRO DE PESQUISA EM EDUCAÇÃO, IV JORNADA DE PRÁTICA DE ENSINO, XIII SEMANA DE PEDAGOGIA DA UEM, Maringá, 2007. Arq. Mudi. Periódicos. 
<http://www.pec.uem.br/pec_uem/revistas/arqmudi/volume_11/suplemento_02/ artigos/019.df >. Acesso em: 10 mai. 2019.

VÁZQUEZ, A.; MANASSERO, M. A. La selección de contenidos para enseñar naturaleza de la ciencia y tecnología (parte 2): una revisión desde los currículos de ciencias y la competencia PISA. Revista Eureka sobre Enseñanza y Divulgación de las Ciencias, Cádiz, v. 9, n. 1, p. 32-53, 2012. Disponível em: <https://revistas.uca.es/index.php/eureka/ article/view/2750>. Acesso em: 14 abr. 2020.

VÁZQUEZ, A.; MANASSERO, M. A. La formación del profesorado sobre temas CTS: un modelo para mejorar sus concepciones. Indagatio Didactica, Aveiro, v. 8, n. 1, p. 110-127, 2016.2 Disponível em: <http://revistas.ua.pt/index.php/ID/article/view/3862/3546>. Acesso em: 14 abr. 2020.

VILCHES, A.; GIL, D. Educación ambiental y educación para el desarrollo sostenible: convergencias y (supuestas) divergencias. In: SEMINÁRIO IBERO-AMERICANO CIÊNCIA-TECNOLOGIA-SOCIEDADE NO ENSINO DAS CIÊNCIAS, 2. e SEMINÁRIO IBÉRICO CTS NO ENSINO DAS CIÊNCIAS, 6., 2010, Brasília. Anais... Brasília: UnB, 2010.

VILCHES, A.; GIL PÉREZ, D.; PRAIA, J. De CTS a CTSA: educação por um futuro sustentável. In: SANTOS, Wilson Luiz Pereira dos; AULER, Décio. CTS e educação científica: desafios, tendências e resultados de pesquisa. Brasília. UNB. p. 161-184. 2011.

VIVEIRO, A. A.; DINIZ, R. E. S. Atividades de campo no ensino das ciências e na educação ambiental: refletindo sobre as potencialidades desta estratégia na pratica escolar. Ciência em tela, Rio de janeiro, v. 2, n. 1, 2009. Disponível em < http://www.cienciaemtela.nutes.ufrj.br/artigos/0109viveiro.pdf $>$ acesso em 10 de março. 2020. 